\title{
Advanced Musculoskeletal Physiotherapy Practice in Ireland: a National Survey.
}

This is the accepted version of the following article: Fennelly, O. Blake, C. FitzGerald, O. Breen, R. O’Sullivan, C. O’Mir, M. Desmeules, F. Cunningham, C. 'Advanced Musculoskeletal Physiotherapy Practice in Ireland: a National Survey.' Musculoskeletal Care, which has been published in final form at doi: $10.1002 / \mathrm{msc} .1351$. This article may be used for non-commercial purposes in accordance with the Wiley Self-Archiving Policy [http://olabout.wiley.com/WileyCDA/Section/id-828039.html]. 


\begin{abstract}
Background: Since 2011, Advanced Practice Physiotherapists (APPs) triage the care of patients awaiting Orthopaedic and Rheumatology Consultant/Specialist Doctor appointments in Ireland. APP services have evolved across the major hospitals $(n=16)$ and after five years, profiling and evaluation of APP services is warranted. This study profiled the national MSK APP services, focusing on: service, clinician, and patient outcome factors.
\end{abstract}

Methods: An online survey of physiotherapists in the allocated APP posts $(n=25)$ explored: service organisation; clinician profile and experience of the advanced role; and patient wait times and outcome measures. Descriptive statistics were used to analyse hospital-specific and clinician-specific data, and a content analysis to explore APP experiences.

Results: A 68\% (n=17) response from 13 sites was achieved, where 20 whole-time APP posts existed in services led by 91 Consultant Doctors. Co-location of APP-Consultant clinics at 11 sites facilitated joint medical-APP processes, with between-site differences in autonomy to screen referral letters, and arrange investigations, injections, and surgery. While $83 \%$ had post-graduate qualifications, APPs also availed of informal role-specific training. Positive APP experiences related to learning opportunities and clinical support networks, but experiences were Consultant-dependent, with further service developments and formal training required to manage workloads. APPs reported reduced wait times and most commonly chose to capture Function/Disability in future evaluations.

Conclusions: Variances existed in organisational design and operating of APP services. Although highly experienced and qualified, APPs welcomed additional formal training and support, due to the complex, more medical nature of APP roles. Further formal evaluation capturing patient outcomes is proposed. 


\section{Introduction}

Increased demands on health services with growing waiting lists, staff and skill shortages, and need for cost containment (McPherson et al., 2006, Jones et al., 2015), together with recognition of the wider clinical expertise and competence of various health disciplines, have driven the transformation of healthcare models with the development of advanced practice health professional roles. Physiotherapy is one such discipline which has broadened its practice remit in the United Kingdom (UK), Canada, New Zealand, Australia, Sweden, and more recently in Ireland (Fennelly et al., 2017). Enhancement in scope of practice sees physiotherapists conducting tasks traditionally more aligned with medical scope of practice, with increased autonomy (Desmeules et al., 2012), to improve patient access to health services. These Advanced Practice Physiotherapists (APPs), formerly known as Extended Scope Practitioners in the UK (CSP, 2016), most commonly operate as part of adult orthopaedic services, but are also found in emergency departments (McClellan et al., 2013), primary care (Goodwin and Hendrick, 2016), and paediatrics (O Mir et al., 2016).

In Ireland, the first national roll-out of an APP service began in 2011, as part of a joint initiative of the National Orthopaedic and Rheumatology Clinical Programmes (Royal College of Physicians, 2012). Twenty-four APP posts were integrated into outpatient orthopaedic and rheumatology services at 16 (55\%) of the 29 public hospitals with an orthopaedic speciality and 15 (71\%) of the 21 public hospitals with a rheumatology service (National Treatment Purchase Fund, 2016). These were the major acute hospitals across all six adult hospital groups in Ireland including six Model 3 (i.e., acute surgery and medicine with a 24/7 emergency departments and critical care), eight Model 4 (i.e., Model 3 services with addition of specialist, supra-regional care) and three Orthopaedic Specialist hospitals (i.e., exclusively elective). While traditionally all patients referred to hospital orthopaedic or rheumatology services by their General Practitioner (GP) (i.e., Primary Care Physician) were assessed by a medical physician, despite not all patients requiring a medical assessment, now the new service development sees APPs triaging the care of patients deemed non-urgent on screening of referral letters.

Physiotherapy scope of practice differs between countries, leading to discrepancies in APP roles. For example, in the UK, physiotherapists with specific additional training are permitted to order diagnostic imaging (Chartered Society of Physiotherapists, 2016b), whereas in Canada, permission to order imaging varies by province (Chong et al., 2015), and in Ireland, physiotherapists do not have image ordering rights. Given that advanced practice represents a 'level of practice' as opposed to a specific role (CSP, 2016), resultant APP service operating procedures are often dependent on individual hospital system policies, hospital regulatory mechanisms and individual Consultant Doctor (i.e., Senior Specialist Doctor) preferences. Variances therefore exist in APP roles, even within the same country (Fennelly et al., 2017, Fennelly et al., 2018), making it difficult to ensure widespread professional recognition and thus, Doctors' confidence in APP triage (King et al., 2017), and generalise research findings to other settings. Due to this diversity, comprehensive evaluation of newly established APP 
services requires inclusion of all APP sites, as well as documentation of tasks performed, autonomy, training and qualifications (Stanhope et al., 2012).

Whilst a National APP Database existed in Ireland to monitor wait time reductions and increased patient through-put (Fennelly et al., 2018), the lack of standardisation of APP services across hospital sites and absence of a registry or defined APP credentials, rendered it difficult to fully interpret and act on findings on a national basis. Profiling of the services and clinicians in Ireland requires gathering of broader data from the APPs themselves across the hospitals sites, with a view to informing ongoing development and provision of training, and enabling further interpretation of the process data. Additionally, the physiotherapist experiences of the new advanced practice role should be explored, with consideration of the potential impact of opportunities for role enhancement and increased responsibilities, on job satisfaction and retention (Weatherley and Hourigan, 1998, Bacopanos and Edgar, 2015).

As well as informing the interpretation of the process-related quality indicators, comparative patient outcome data should be collected. Wait time data prior to establishment of APP services is required from each site, as pre-2012 national data on wait times were not accessible. As well as reducing wait times by increasing workforce capacity, implementation of this new inter-professional model of care has potential to improve patient outcomes. Further research on patient-reported outcome measures (PROMs) is necessary and requires investigation of what is currently captured by APPs and what is deemed important (Fennelly et al., 2017).

The main aim of this study was to profile the clinical organisation and scope of the national MSK APP triage service in Ireland across hospital sites. The objectives were to profile: (i) Service Factors (i.e., organisational design); (ii) Clinician Factors (i.e., APP demographics, responsibilities, ex perience); and (iii) Patient Outcome Factors (i.e., wait times and PROMs).

\section{Methods}

\section{Survey population}

In February 2016, an online survey (Google Forms) was distributed to all physiotherapists $(n=25)$ in the advanced practice posts commissioned by the National Clinical Programmes, across all 16 hospital sites in Ireland. Follow-up reminders were sent to non-respondents at two weeks, and again at three weeks.

Questionnaire development 
The questionnaire was specifically-designed by two authors [OF and CC], and informed by stakeholder consultation and current APP literature (Morris et al., 2015, Saxon et al., 2014, Syme et al., 2013, Griffiths et al., 2012), with minor amendments made following a pilot with three APPs. Thirty-two questions, including a variety of closed multiple response option and open-ended questions, explored: (1) APP triage service characteristics; (2) Clinician qualifications and practice characteristics; (3) Clinician experience (positives and challenging aspects) of the advanced practice role; and (4) Patient outcome data (i.e., 2011 and 2016 wait times, and PROMs collected and deemed important).

Data analysis

Data were coded, entered into the Statistical Package for the Social Sciences (SPSS), version 20.0 and analysed using descriptive statistics. Service factors were grouped by hospital site and compared to avoid duplication in reporting, and clinician factors of each individual APP were analysed. At sites where APPs reported both pre and post MSK service wait times, mean changes in wait times were evaluated.

Qualitative data from the open-ended questions were analysed using an inductive content analysis (Graneheim and Lundman, 2004). Two authors [OF and CC] examined the data independent of each other and coded it, with codes compared and consensus reached via discussion where required. Codes were grouped into mutually exclusive themes, and responses reviewed on a continuous basis to ensure that no manifestations of themes were missed, and that no code was excluded.

\section{Ethical approval}

Full ethical approval was received from University College Dublin's Human Research Ethics Committee, with permission from the National Clinical Programmes for Rheumatology and for Orthopaedics.

\section{Results}

\section{Service factors}

Responses were obtained from APPs at 13 of the $16(81.3 \%)$ hospital sites regarding the organisational design of APP orthopaedic and rheumatology services. 
Across the 13 hospital sites, 20 whole time equivalent (WTE) APPs worked with 66 Orthopaedic Consultants and 25 Consultant Rheumatologists (Fig. 1). At this time, a further 10 Orthopaedic Consultants and 10 Consultant Rheumatologists at these 13 hospitals were not participating in the national MSK APP services. While not represented in Figure 1, four sites had created additional triage physiotherapy posts distinct from the national APP service.

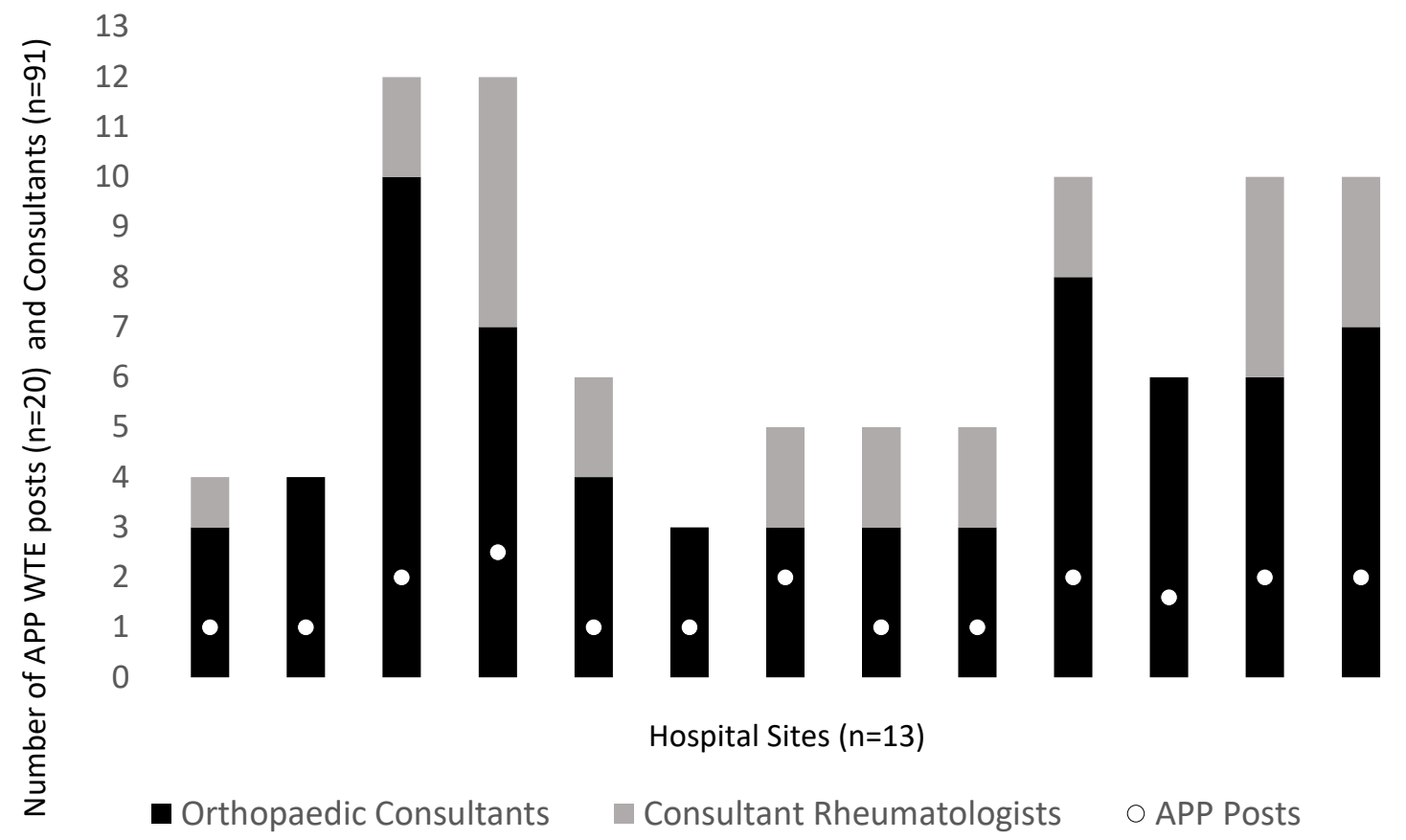

Note: WTE, Whole Time Equivalent.

Figure 1. Advanced Practice Physiotherapists (APPs) and Consultant Doctors participating in the National MSK Initiative in 2016

\section{Clinical Pathway}

GP referral letters to participating Orthopaedic and Rheumatologist Consultants were usually screened to determine appropriateness for an APP versus Consultant Doctor appointment, but three sites (19\%) allowed direct referrals from GPs to the APP service. At the time of the APP appointment, Consultant Doctor input on clinical decisions could usually be acquired if needed, and this was facilitated by colocation of APP and Consultant clinics ( $n=11 ; 85 \%)$, as opposed to the APP clinic being situated in the physiotherapy department $(n=2 ; 15 \%)$. Follow-up appointments required for injections, interpretation of investigation results, or Consultant Doctor input, were shorter (<30minutes) than new appointments ( $<45$ minutes), and at eight sites $(62 \%)$, self-referral by patients for return appointments was permitted if their specific condition had deteriorated within one year. 


\section{Clinician Factors}

\section{APP demographics}

Seventeen APPs (68\%) responded to the national survey. All had more than five years clinical MSK experience with the majority in the APP post for more than 2 years (Table 1), in a full-time capacity $(\mathrm{n}=13 ; 76 \%)$. While most had a postgraduate degree (Table 1$)$, additional role-specific training had been provided via consultant doctor shadowing and mentoring $(n=14 ; 82 \%)$, as well as a bespoke Health Service Executive course $(n=7 ; 41 \%)$ and training from another APP $(n=3 ; 18 \%)$. Other continuous professional development (CPD) courses on radiology, blood tests, injection therapy and a visit to a UK APP centre of excellence, were also reported.

Table 1 Professional profile of Advanced Practice Physiotherapists $(n=17)$

\begin{tabular}{|c|c|}
\hline & $\begin{array}{l}\text { APPs } \\
\text { n (\%) }\end{array}$ \\
\hline \multicolumn{2}{|l|}{ Sex } \\
\hline Female & $12(71)$ \\
\hline \multicolumn{2}{|l|}{ Highest education level } \\
\hline $\mathrm{PhD}$ & $2(\mathbf{1 2})$ \\
\hline Masters & $12(71)$ \\
\hline Bachelors & $2(12)$ \\
\hline Diploma & $1(6)$ \\
\hline \multicolumn{2}{|l|}{ Clinical experience } \\
\hline$>15$ years & $13(\mathbf{7 6})$ \\
\hline $10-15$ years & $3(\mathbf{1 8})$ \\
\hline $5-10$ years & $1(6)$ \\
\hline \multicolumn{2}{|c|}{ Specific musculoskeletal experience } \\
\hline$>10$ years & $13(\mathbf{7 6})$ \\
\hline $5-10$ years & $4(24)$ \\
\hline \multicolumn{2}{|l|}{ Years in APP post } \\
\hline$>2$ years & $14(\mathbf{8 2})$ \\
\hline$<2$ years & $3(18)$ \\
\hline Injection therapy qualification & $7(41)$ \\
\hline
\end{tabular}

\section{APP responsibilities}

Each APP worked with more than one Consultant Doctor, usually in both orthopaedic and rheumatology triage $(n=10 ; 59 \%)$, with fewer working solely in orthopaedic $(n=6 ; 35 \%)$ or rheumatology triage $(n=1$; 
6\%); this included one APP working in orthopaedic paediatrics. Variances occurred in APP level of autonomy to screen referral letters, order clinical investigations and list for surgery. Ten APPs (59\%) reported screening some GP referral letters to select appropriate patients for the APP clinic, while only one APP (6\%) had delegated authority to order clinical imaging. All other APPs $(n=16 ; 82 \%)$ arranged $\mathrm{X}$-rays via discussion with a doctor, while some APPs most commonly referred patients for a doctor's appointment to arrange a Computed Tomography (CT), Magnetic Resonance Imaging (MRI), Ultrasound (US) or Neurophysiological tests (Table 2). In most cases where surgery was indicated, APPs referred patients to an Orthopaedic Consultant, but two APPs could list patients for an US-guided injection (Table 2).

Table 2 Advanced Practice Physiotherapist (APP) procedures for requesting clinical investigations/surgery ( $=17)$

\begin{tabular}{|c|c|c|c|c|c|c|c|c|}
\hline & MRI & CT & X-ray & US & $\begin{array}{r}\text { Neurophysiol- } \\
\text { ogical tests }\end{array}$ & $\begin{array}{l}\text { Bloods } \\
(\mathrm{n}=5)^{\phi}\end{array}$ & $\begin{array}{l}\text { US-guided } \\
\text { Injection }\end{array}$ & Surgery \\
\hline & n (\%) & $\mathrm{n}(\%)$ & n (\%) & $\mathrm{n}(\%)$ & n (\%) & $n(\%)$ & $n(\%)$ & n (\%) \\
\hline \multicolumn{9}{|l|}{ Procedure } \\
\hline APP refers for doctor assessment & 1 ( 6) & $7(41)$ & $0(0)$ & $2(14)$ & $3(18)$ & $0(0)$ & $7(41)$ & $14(82)$ \\
\hline $\begin{array}{l}\text { Following discussion with APP, } \\
\text { Doctor orders investigation or lists } \\
\text { patient for surgery }\end{array}$ & $15(88)$ & 10 (59) & $16(94)$ & $14(82)$ & $9(53)$ & $3(60)$ & $8(47)$ & $3(18)$ \\
\hline APP delegated authority & 1 ( 6) & $0(0)$ & $1(6)$ & $1(6)$ & $5(29)$ & $2(40)$ & $2(12)$ & $0(0)$ \\
\hline
\end{tabular}

Note: MRI, Magnetic Resonance Imaging; CT, Computed Tomography; US, Ultra-sound; ' Procedure for requesting Blood Tests included in five questionnaires only.

Although operating primarily in a triage role, most APPs $(n=15 ; 88 \%)$ provided physiotherapy treatment (i.e., exercise, manual therapy) to a small proportion of their patients. Physiotherapy referral pathways available to APPs: primary care $(n=16)$; the same hospital $(n=16)$; other hospitals $(n=12)$; or private practices $(n=5)$; were influenced by the patient's previous physiotherapy input and availability of physiotherapy services in their geographical location.

\section{APP experiences of the role}

Physiotherapists $(n=12 ; 71 \%)$ reported both positive and challenging aspects in their experience of the advanced practice roles, relating to both training provided and current service operating procedures. The following themes were identified: 
Increased interdisciplinary communication and support

The APP service has improved communication channels between the medical team and physiotherapists regarding patient care. APPs have experienced support for their role from Medical, Nursing and Physiotherapy colleagues, and one APP noted the benefit of working with another APP at the same site for support.

"Increased communication between the orthopaedic consultants and physiotherapy department at this centre." [APP working in orthopaedic triage for 3.5 years]

“Positive: Working as part of a team rather than alone." [APP working across orthopaedic and rheumatology triage for 2.5 years]

\section{Need for service development}

The MSK APP services were regarded as having further potential for development such as moving to primary-secondary care interface model. However, frustration existed amongst the APPs regarding lack of autonomy to order imaging, and the service focus remaining on the number of patients seen and waiting lists, rather than on patient outcomes. Further service development with legislative changes to allow APPs to order clinical imaging was deemed important by the APPs, as well as "further research and development time built into allocated system" [APP working in orthopaedic triage for 2.5 years].

"Post holders have much more potential to operate autonomously were they able to order investigations and trained appropriately in image interpretation." [APP working across orthopaedic and rheumatology triage for 4 years]

\section{Learning opportunities}

Multiple opportunities to develop skills outside of the traditional physiotherapy role were seen as a positive aspect of the advanced practice role. These informal learning opportunities stemmed from the challenging caseload and included: clinical investigation interpretation; determining surgical threshold; and service development skills.

"Enhances knowledge of surgical thresholds and imaging interpretation." [APP covering leave in orthopaedic and rheumatology triage] 
"Huge increase in my knowledge of MSK conditions, role for imaging, role of orthopaedics, role of other tests. Much more aware of strategic challenges required to set up a service." [APP working across orthopaedic and rheumatology triage for 4 years]

\section{Formal training required}

APPs reported limited availability of formal training for the advanced practice role. Further investment in CPD programmes was deemed necessary, including those on clinical imaging and other skills, such as leadership. One APP also noted that maintaining clinical physiotherapy skills through formal educational programmes was also important for those in advanced practice roles.

"Lack of CPD opportunities for this role within Ireland." [APP working across orthopaedic and rheumatology triage for 2.5 years]

\section{Consultant Doctor-dependent}

The advanced practice training and operating of the APP service depended highly on the Consultant Doctors participating. APPs reported that with time, Consultants gained confidence in the physiotherapist's ability and engaged more in the APP service. However, this presented difficulties for APPs covering leave who had to learn "on the hoof" [APP covering leave in orthopaedic and rheumatology triage].

"Each hospital consultant has a different approach in their clinics and it takes time to build a good relationship, which eventually makes the clinic run more smoothly." [APP working in orthopaedic triage for 2.5 years]

\section{Large workload}

Challenging caseloads and lack of administrative support for APPs resulted in "significant workloads in terms of admin (referral triaging/scheduling/letters/follow up)" [APP working across orthopaedic and rheumatology triage for 4 years]. Larger demands were also placed on APPs working in rheumatology services which were more "time-consuming" than orthopaedic services, and at sites where an increase in the number of Consultant Doctors participating resulted in longer waiting lists for APPs. Without an increase in support for the APPs to deal with the demands of this role, there was a risk of job "burn out 
for physiotherapists" [APP working across orthopaedic and rheumatology triage for 4 years].

\section{Patient Outcome Factors}

\section{MSK wait times}

In 2011, prior to the implementation of APP services, APPs at six hospital sites reported a mean wait time of 20.7 months for an orthopaedic appointment, compared to a mean of 4.7 months at 11 sites in 2016. Similarly, the mean rheumatology wait time in 2011 was reportedly 15.2 months at six sites, compared with 4.6 months in 2016 across 10 sites. This represents a mean reduction of 16.2 months for orthopaedic services at six sites, and 10.8 months for rheumatology services at six sites.

\section{Patient-reported outcome measures (PROMs)}

Seven APPs routinely collected PROMs at the time of assessment, to inform patient management. PROMs utilised were for the assessment of: pain (Numerical Rating Scale; Visual Analogue Scale); quality of life (Health Assessment Questionnaire); depression and anxiety (Hospital Anxiety and Depression Scale); Carpal Tunnel Syndrome (Clinical Questionnaire for the Diagnosis of Carpal Tunnel Syndrome); Ankylosing Spondylitis (Bath Ankylosing Spondylitis Functional Index); Rheumatoid Arthritis (Disease Activity Score); Osteoarthritis of the hip and knee (Oxford Score; Hip Disability and Osteoarthritis Outcome Score) and back pain (STarT Back Tool). To monitor service efficiency in future evaluations, APPs $(n=15)$ most commonly selected the health dimension 'Function/Disability' and chose relevant PROMs which could be used (Table 3), but the feasibility of collection requires further investigation.

Table 3. Patient reported outcome measure (PROM) health dimensions selected for use in future evaluations by the

\begin{tabular}{lr} 
Advanced Practice Physiotherapists (APPs) & APPs (n=17) \\
\hline Health Dimension & $1 \%)$ \\
(PROMs suggested) & $13(\mathbf{7 2})$ \\
\hline $\begin{array}{l}\text { Function/Disability } \\
\text { (Patient specific functional scale, Global Perceived Change, SPADI, DASH, Oxford Shoulder Score, }\end{array}$ & \\
STarT Back Tool, RMQ, ODI, Index for severity for osteoarthritis of the hip) & $11(\mathbf{6 5})$ \\
Pain & \\
(NRS, VAS, Orebro) & $10(\mathbf{5 9})$ \\
Quality of Life & \\
(SF-36; SF-16; EuroQoL) & $8(\mathbf{4 7})$ \\
$\begin{array}{l}\text { Depression/Anxiety } \\
\text { (HADS) }\end{array}$ & $6(\mathbf{3 5})$ \\
Disease Specific & \\
(Carpal Tunnel Questionnaire) & $5(\mathbf{2 9})$ \\
\hline
\end{tabular}




\section{Discussion}

This was the first study to detail the organisation and scope of the MSK APP clinical service in Ireland, and it demonstrated the discrepancies existing between services at different sites. It is common for the operating of APP services to vary and depend on Consultant preferences, as Consultant Doctors take ultimate responsibility for patient care (Dawson and Ghazi, 2004). The APPs conducted advanced practice tasks with varying levels of autonomy and responsibility, in relation to referral letter screening, injection therapy, and arranging investigations and surgery. Similar to previous findings (Stamm and Hill, 2011, Dawson and Ghazi, 2004), the advanced practice role allowed for professional development, with increased knowledge and growth in interdisciplinary networks and support. However, the APP workload was regarded as heavy, with deployment of more formal training opportunities and supports warranted.

Individual hospital needs and clinic space, influenced the organisational design of APP services, resulting in discrepancies between sites including: the number of Consultant Doctors and APPs participating; GP referral access; and the location of APP clinics. With time, Consultant Doctors gained more confidence in APP services and this positively encouraged more Consultants to participate, bringing additional patient numbers to APP waiting lists. This increased workload for APPs requires adequate access to administrative support, clinical investigations, injection therapy, and surgical reviews. Co-location of APP-Consultant clinics alleviates any barriers to Consultant input for these medical services and onward referrals (Holdsworth et al., 2008), as well as supporting its clinical governance. These organisational factors influence the efficiency of APP services and need to be taken into account when comparing the process-related outcomes between services.

Despite a lack of credentialing for APPs in Ireland, all the physiotherapists had extensive MSK experience consistent with the UK Chartered Society of Physiotherapists criteria (Chartered Society of Physiotherapists, 2016a), and the majority had a post-graduate qualification at $\mathrm{MSc} / \mathrm{PhD}$ level, most of which had been self-funded. However, the additional responsibilities of the role required role-specific 
training, most commonly accessed on ad hoc basis both in Ireland and in the UK (Gilmore et al., 2011, Weatherley and Hourigan, 1998). This is important for building working relationships with Consultants, becoming embedded in the medical team, and receiving appropriate medical training (Dawson and Ghazi, 2004, O Mahony and Blake, 2016, Holdsworth et al., 2008). However, provision of dedicated, formal training programmes to become an APP is welcomed and would improve transparency of career progression paths and doctors' confidence in MSK triage services (Holdsworth et al., 2008, Moffatt et al., 2017, O Sullivan and Doody, 2014), as well as supporting the case for formal CPD funding and enhancement of remuneration for APPs, who take on responsibilities which lie beyond traditional physiotherapy practice.

While some APPs had autonomy to conduct tasks such as arranging investigations and administering injections, the slow progression in formal changes to physiotherapy scope of practice has led to frustration amongst APPs, who found their expertise undermined. Ordering clinical investigations is deemed an important aspect of the triage role (O Mahony and Blake, 2016), and changes to legislation, coupled with formal training courses, are required to allow greater physiotherapy autonomy. These changes have already occurred in the UK, where physiotherapists have limited medication prescription rights, and will soon be permitted to certify fitness to work (Chartered Society of Physiotherapists, 2012). This would also improve service efficiency by reducing interruptions to Doctors' clinical time.

As well as lessening patient wait times, opportunities for health professionals to progress their careers and access interdisciplinary learning, improves their job satisfaction (Thom, 2018, Bacopanos and Edgar, 2015). However, experiences of the advanced practice role were dependent on Consultant Doctors, and to ensure job retention and prevent burnout, adequate support must be provided to APPs. Additional complexity and learning needs existed for those working across two specialities (orthopaedics and rheumatology), and those working with up to six different Consultant Doctors, who specialise in different MSK conditions and have differing clinic operating procedures. Necessary support may be achieved through having more formal learning opportunities, multiple APPs situated at the same site, greater administrative staff support, and most importantly, support from the Consultant Doctors themselves (O Mahony and Blake, 2016).

APPs were also frustrated that the service remained focused on wait times and patient throughput, rather than on patient-focused outcomes. This lack of emphasis on patient outcomes, is also reflected in international literature (Fennelly et al., 2017, Comans et al., 2011). Further research comparing the effects of different service designs and operating procedures on the patient outcomes, such as APPs providing follow-up physiotherapy treatment, would identify the most efficacious model of care. Although Patient-reported outcome measures (PROMs) deemed important by APPs were identified, further service development time was required for collection and analysis.

\section{Strengths and Limitations}


Although a high survey response rate was achieved across hospital sites (81.3\%) and from individual APPs (68\%) (Baruch and Holtom, 2008), three hospital sites with seven APPs in post, did not respond, and a more in-depth exploration of APP experiences and validation of wait times is required. Nevertheless, for the first time a national APP service has been profiled from the APP perspective, and this will inform further research regarding the most efficient and effective clinical pathways, and allow international comparisons (Stanhope et al., 2012).

\section{Conclusion}

Although implemented on a national level, discrepancies existed in the operating of APP services. All APPs had extensive MSK clinical experience and qualifications, but their level of autonomy to conduct advanced tasks such as ordering clinical imaging, depended on Consultant Doctor preferences and individual hospital policies. Positive role aspects included increased inter-disciplinary communication, support and learning opportunities, but further availability and investment in formal education and training programmes is required, which would enhance APP career pathways. Finally, further evaluation and focus on patient-focused outcomes was recommended to support the new APP services. 


\section{References}

Bacopanos, E. \& Edgar, S. 2015. Identifying the factors that affect the job satisfaction of early career Notre Dame graduate physiotherapists. Australian Health Review 40, 538-543.

Baruch, Y. \& Holtom, B. C. 2008. Survey response rate levels and trends in organizational research. Human Relations, 61, 1139-1160.

Chartered Society of Physiotherapists. 2012. Physiotherapists gain new power to prescribe medicines independently after campaigning by CSP [Online]. Available at: http://www.csp.org.uk/pressreleases/2012/07/24/physiotherapists-gain-new-power-prescribe-medicines-independentlyafter-ca [Accessed].

Chartered Society of Physiotherapists. 2016a. Advanced practice in physiotherapy: understanding the contribution of advanced practice in physiotherapy to transforming lives, maximising independence and empowering populations. Available at: http://www.csp.org.uk/sites/files/csp/secure/csp_advanced_practice_physiotherapy_2016_2.p $\underline{\mathrm{df}}$

Chartered Society of Physiotherapists. 2016b. Medicines, Prescribing and Physiotherapy 4th Ed. Available at: http://www.csp.org.uk/publications/medicines-prescribing-physiotherapy-4thedition

Chong, J. N., De Luca, K., Goldan, S., Imam, A., Li, B., Zabjek, K., Chu, A. \& Yeung, E. 2015. Ordering diagnostic imaging: a survey of ontario physiotherapists' opinions on an expanded scope of practice. Physiotherapy Canada, 67, 144-56.

Comans, T., Clark, M., Cartmill, L., Ash, S. \& Sheppard, L. 2011. How do Allied Health Professionals evaluate new models of care? What are we measuring and why? Journal of Healthcare Quality, 33, 19-28.

Csp. 2016. Advanced practice in physiotherpy: Understanding the contribution of advanced practice in physiotherapy to transforming lives, maximising independence and empowering populations. Available

at: file:///C:/Users/Fenne/Downloads/csp_advanced_practice_physiotherapy_2016_2\%20(1).pdf

Dawson, L. J. \& Ghazi, F. 2004. The experience of physiotherapy extended scope practitioners in orthopaedic outpatient clinics. Physiotherapy, 90, 210-216.

Desmeules, F., Roy, J. S., Mac Dermid, J. C., Champagne, F., Hinse, O. \& Woodhouse, L. J. 2012. Advanced practice physiotherapy in patients with musculoskeletal disorders: a systematic review. BMC Musculoskelet Disorders, 13, 107.

Fennelly, O., Blake, C., Desmeules, F., Stokes, D. \& Cunningham, C. 2017. Patient Reported Outcome Measures in Advanced Musculoskeletal Physiotherapy Practice: A Systematic Review. Musculoskeletal Care, 16, 188-208.

Fennelly, O., Blake, C., Fitz Gerald, O., Breen, R., Ashton, J., Brennan, A., Caffrey, A., Desmeules, F. \& Cunningham, C. 2018. Advanced practice physiotherapy-led triage in Irish orthopaedic and rheumatology services: national data audit. BMC Musculoskeletal Disorders, 19, 181.

Gilmore, L. G., Morris, J. H., Murphy, K. \& Kumar, S. 2011. Skills escalator in allied health: a time for reflection and refocus. Journal of Healthcare Leadership, 3, 53-58.

Goodwin, R. \& Hendrick, P. 2016. Physiotherapy as a first point of contact in general practice: a solution to a growing problem? Primary Health Care Research and Development 17, 289-502.

Graneheim, U. H. \& Lundman, B. 2004. Qualitative content analysis in nursing research: concepts, procedures and measures to achieve trustworthiness. Nurse Educ Today, 24, 105-12.

Griffiths, S., Taylor, C. \& Yohannes, A. M. 2012. Conversion rates and perceived barriers to referral: views of extended scope physiotherapists in the primary care setting. Musculoskeletal Care, 10, 221-31.

Holdsworth, L. K., Webster, V. S. \& Mc Fadyen, A. K. 2008. Physiotherapists' and general practitioners' views of self-referral and physiotherapy scope of practice: results from a national trial. Physiotherapy, 94, 236-243.

Jones, A., Powell, T., Watkins, D. \& Kelly, D. 2015. Realising their potential? Exploring interprofessional perceptions and potential of the advanced practitioner role: a qualitative analysis. BMJ Open, 5, e009740. 
King, R., Tod, A. \& Sanders, T. 2017. Development and regulation of advanced nurse practitioners in the UK and internationally. Nursing Standard, 32, 43-50.

Mcclellan, C. M., Cramp, F., Powell, J. \& Benger, J. R. 2013. Extended scope physiotherapists in the emergency department: a literature review. Physical Therapy Reviews, 15, 106-111.

Mcpherson, K., Kersten, P., George, S., Lattimer, V., Breton, A., Ellis, B., Kaur, D. \& Frampton, G. 2006. A systematic review of evidence about extended roles for allied health professionals. Journal of Health Service Research and Policy, 11, 240-7.

Moffatt, F., Goodwin, R. \& Hendrick, P. 2017. Physiotherapy-as-first-point-of-contact-service for patients with musculoskeletal complaints: understanding the challenges of implementation. Primary Health Care Research and Development, 19, 1-10.

Morris, J. H., James, R. E., Davey, R. \& Waddington, G. 2015. What is orthopaedic triage? A systematic review. Journal of Evalualtion in Clinical Practice, 21, 128-36.

National Treatment Purchase Fund. 2016. The National Treatment Purchase Fund: Outpatient/Waiting list [Online]. Available at: http://www.ntpf.ie/home/outpatient.htm [Accessed 9th June 2016].

O Mahony, N. \& Blake, C. 2016. Musculoskeletal triage: The experiences of advanced practice physiotherapists in Ireland. Physiotherapy Practice and Research, 38, 7-16.

O Mir, M., Cooney, C., O Sullivan, C., Blake, C., Kelly, P., Kiely, P., Noel, J. \& Moore, D. 2016. The efficacy of an extended scope physiotherapy clinic in paediatric orthopaedics. Journal of Children Orthopedics, 10, 169-175.

O Sullivan, S. \& Doody, C. 2014. Orthopaedic surgeons' views of physiotherapy extended scope practitioners in Ireland. Irish Journal of Medical Science 183, S108.

Royal College of Physicians. 2012. About the National Clinical Programmes [Online]. Available at: https://www.rcpi.ie/article.php?locID=1.10.410.496 [Accessed 16th February 2016].

Saxon, R., Gray, M. \& Oprescu, F. 2014. Extended roles for allied health professionals: an updated systematic review of the evidence. Journal of Multidisciplinary Healthcare, 7, 479-88.

Stamm, T. \& Hill, J. 2011. Extended roles of non-physician health professionals and innovative models of care within Europe: results from a web-based survey. Musculoskeletal Care, 9, 93-101.

Stanhope, J., Grimmer-Somers, K., Milanese, S., Kumar, S. \& Morris, J. 2012. Extended scope physiotherapy roles for orthopedic outpatients: an update systematic review of the literature. Journal of Multidisciplinary Healthcare, 5, 37-45.

Syme, G., Rutter, M., Suckley, J., Payne, C. \& Russell, V. 2013. Resource Manual and Competences for Extended Musculoskeletal Physiotherapy. Available at: www.esp-physio.co.uk/

Thom, S. E. 2018. Does advanced practice in radiography benefit the healthcare system? A literature review. Radiography (Lond), 24, 84-89.

Weatherley, C. R. \& Hourigan, P. G. 1998. Triage of back pain by physiotherapists in orthopaedic clinics. Journal of the Royal Society of Medicine, 91, 377-379. 